\title{
Hepatoprotective effect of gallic acid against type 2-induced diabetic liver injury in male rats through modulation of fetuin-A and GLP-1 with involvement of $\mathrm{ERK}_{1 / 2} / \mathrm{NF}-\mathrm{KB}$ and $\mathrm{Wnt} 1 / \beta$-catenin signaling pathways
}

\author{
Shaimaa M. Bashar ${ }^{1}$, Mona G. Elhadidy ${ }^{1}$, Abeer F. Mostafa ${ }^{1}$, Basma Hamed ${ }^{2}$, Soheir Helmy ${ }^{1}$ \\ and Hanaa A. Abd-Elmoniem ${ }^{1}$ \\ ${ }^{1}$ Department of Medical Physiology, Faculty of Medicine, Mansoura University, Mansoura, Egypt \\ ${ }^{2}$ Veterinary Surgeon at Medical Experimental Research Center, Faculty of Medicine, Mansoura University, Mansoura, Egypt
}

\begin{abstract}
Gallic acid is a phenolic compound with biological and pharmacological activities. Therefore, our study aimed to examine whether gallic acid has a beneficial effect against type 2 -induced diabetic hepatic injury in rats and attempt to discover its possible intracellular pathways. Adult male rats were subdivided into six groups: Control, DM (diabetes mellitus), GA (gallic acid)+DM, $\mathrm{DM}+\mathrm{GA}, \mathrm{DM}+\mathrm{MET}$ (metformin) and DM+GA+MET. Type 2 diabetes mellitus (T2DM) induced a significant increase in the blood glucose, HOMA-IR, liver enzymes, fetuin-A, hepatic triglycerides content with diminished serum insulin and hepatic glycogen content associated with impairment of cellular redox balance. Administration of gallic acid successfully restored all these alterations which was confirmed by marked improvement of the histopathological changes of the liver. Significantly, gallic acid increased the expression of glucagon-like peptide-1 (GLP-1) immunoreactive cells in the terminal ileum with negative correlation observed between fetuin-A and GLP-1 cells. Furthermore, our results discovered that gallic acid could diminish the DM-induced hepatic damage via upregulated hepatic mRNA expression of GLUT-4, Wnt1 and $\beta$-catenin with inhibitory effects on the elevated expression of $\mathrm{ERK}_{1 / 2} / \mathrm{NF}-\mathrm{\kappa B}$. In conclusion, this study suggests that gallic acid provides a significant protection against T2DM-mediated liver injury. The use of gallic acid with traditional anti-diabetic drug enhanced its efficiency compared with traditional drug alone.
\end{abstract}

Key words: Gallic acid - Fetuin-A - ERK $1 / 2-\mathrm{NF}-\kappa \mathrm{B}-$ GLUT- $4-$ Wnt1 $-\beta$-catenin

\section{Introduction}

Type 2 diabetes mellitus (T2DM) is the most common type of diabetes worldwide that has three main characteristics features; hyperglycemia, insulin resistance and impaired islet cell function (American Diabetes Association 2014). Hepatic insulin resistance has been characterized by a reduction of insulin-stimulated signal transduction pathways for hepatic glucose production (Petersen and Shulman 2018). Many factors are known to be causative for the development of insulin

Correspondence to: Mona G. Elhadidy, Department of Medical Physiology, Faculty of Medicine, 24 Gomhouria St., Mansoura 35516, Egypt

E-mail: mona.gaber2012@yahoo.com resistance in the liver such as, hepatitis $C$ virus, obesity, T2DM and non-alcoholic fatty liver disease (NAFLD). While NAFLD increases the incidence of T2DM and the occurrence of its complications, also, T2DM accelerates progression of NAFLD towards steatosis, cirrhosis and hepatocellular carcinoma (i.e. vicious circle) (Loria et al. 2013). In general, high concentrations of lipids and specific lipid derivatives such as ceramides or diacylglycerols, a characteristic feature of NAFLD, are known to exert toxic effects on the liver cells. Furthermore, chronic hyperglycemia in T2DM is associated with the accumulation of triglycerides in the hepatocytes. This chronic hyperglycemic state also associated with activation of lipogenic enzymes and induction of endoplasmic stress, eventually resulting in steatosis and cell death (Mota et al. 2016). Therefore, attenuating this complication of 
T2DM is equally as important as decreasing blood glucose levels in long-term therapies. Moreover, basic and clinical data illustrated that NAFLD can lead to development of T2DM via insulin resistance (IR), particularly hepatic IR. Conversely, T2DM may lead to progression of liver disease. Presently, there is no medication that approved for NAFLD. Several medicines have been suggested, but none of them have shown significant beneficial effects against the liver damage (Rotman and Sanyal 2017). Weight loss and lifestyle modification have usually been applied for the treatment of NAFLD but are often difficult to maintain for all patients (Song et al. 2020). Therefore, there is an immediate need to classify drugs that are safe for long-term administration, targeting increased hepatic fat in T2DM.

Fetuin-A is a serum glycoprotein that is synthesized and secreted by the liver. In obesity and its complications, such as T2DM, metabolic syndrome and NAFLD, elevated circulating fetuin-A are regularly observed. In addition, fetuin-A levels are correlated with many metabolic disease-related parameters, such as insulin sensitivity, glucose tolerance and circulating lipid levels (Trepanowski et al. 2015).

Glucagon-like peptide (GLP-1) is a 30 -amino acids hormone that is synthesized and secreted from the enteroendocrine L-cells, this hormone stimulates the secretion of glucose-dependent insulin from $\beta$-cells of the pancreas. T2DM treatment with GLP has also been reported to enhance $\beta$-cell activity, normalize blood glucose levels and restore insulin secretion, so GLP-1 and its receptors are therapeutic targets for the treatment of T2DM (Bhat et al. 2018). GLP-1 additionally induces the synthesis of glycogen in the liver. It also improves the oxidation of fatty acids and the removal of lipids from hepatocytes, reducing de novo lipogenesis. Studies indicate that this hormone can be used to treat a variety of liver disorders, such as NAFLD or nonalcoholic steatohepatitis (NASH) (Loomba and Sanyal 2013).

Gallic acid is a phenolic compound also known as 3,4,5-trihydroxybenzoic acid. It is found both as a free state and as a constituent of tannins, namely, gallotannin. In nearly every part of the plant, such as bark, wood, leaf, fruit, root, and seed, gallic acid and its derivatives are present (Kahkeshani et al. 2019). In addition to the edible uses of gallic acid and its ester derivatives in the food industry as flavoring agents and preservatives, numerous scientific studies identify its biological and pharmacological activities, such as its antioxidant, antimicrobial, anti-inflammatory and anti-neoplastic effects, as well as gallic acid has therapeutic activities against gastrointestinal, neuropsychological, metabolic and cardiovascular disorders (Choubey et al. 2015).

Therefore, the purpose of the present study was to determine the possible effects of the administration of gallic acid on the type 2 induced-diabetic liver injury rat model and the possible involvement of fetuin-A and GLP-1 in their mechanism of action and their correlation. In addition, the alternative signaling mechanisms underlying the beneficial effects of gallic acid on the liver have been explored by modulating ERK $_{1 / 2} / \mathrm{NF}-\kappa \mathrm{B}$ and Wnt $1 / \beta$-catenin.

\section{Material and Methods}

\section{Chemicals and drugs}

Streptozotocin (STZ), gallic acid, metformin hydrochloride, glucose, insulin rats ELISA kits, fetuin-A rats ELISA kits and GLP-1 antibodies were used in this study. STZ was purchased from Sigma (St. Louis, MO, USA) and stored at $-20^{\circ} \mathrm{C}$ in a dark bottle. Gallic acid and metformin were purchased from Alpha Aesar Company (USA).

\section{Experimental animals}

Sixty adult male healthy Sprague Dawley rats (age between 3-4 months and weighing about $180 \pm 20 \mathrm{~g}$ ) were enrolled in this study. Animals were brought from and housed in the Medical Experimental Research Center (MERC), Faculty of Medicine, Mansoura University, Egypt. They were remained under observation for acclimatization one week before the onset of the experimental study. The selected animals were housed in plastic cages with good aeration at room temperature $\left(24 \pm 2^{\circ} \mathrm{C}\right)$, humidity $(50 \pm 5 \%)$ and 12 hours' light/dark cycle. The protocol of this experimental study was conducted according to the Guide for the Care and Use of Laboratory Animals (8th edition, National Academies Press). Also, our local committee of animal care and used in Mansoura Faculty of Medicine approved this protocol (Code number MDP.19.10.28).

\section{Experimental design}

The rats were randomly divided into six groups: 1) Control group (C), rats were fed control diet ( $10 \%$ of total calories from fat; $3.7 \mathrm{kcal} / \mathrm{g}$ diet); 2) DM group, high fat diet (HFD) for 4 weeks then single injection of STZ ( $35 \mathrm{mg} / \mathrm{kg}$ ) and HFD for 4 week; 3) GA+DM group, gallic acid was given by gavage $(20 \mathrm{mg} / \mathrm{kg} /$ day, dissolved in distilled water) (Latha and Daisy 2011) concomitant with induction of T2DM and continued for 8 weeks; 4) DM+GA group and 5) DM+MET group, both groups received HFD for 4 weeks then single injection of STZ, gallic acid ( $20 \mathrm{mg} / \mathrm{kg} /$ day) and metformin by gavage $(200 \mathrm{mg} /$ $\mathrm{kg} /$ day, dissolved in distilled water) (Xiao et al. 2019) with HFD for another 4 weeks, respectively; 6) DM+GA+MET group received HFD for 4 weeks then single injection of STZ and gallic acid (20 mg/kg/day) plus metformin $(200 \mathrm{mg} / \mathrm{kg} /$ day) for another 4 weeks. Fasting blood glucose of all rats was measured weekly from rat tail vein during whole experimental period using glucometer (Accu-Chek Performa Meter, 140 
Roche, Germany). Furthermore, body weight of all rats was recorded at the beginning (initial) and at the end (final) of the experimental period. At the end of the study, the animals were fasted for $12 \mathrm{~h}$, then anesthetized with intraperitoneal injection of sodium thiopental at a dose of $50 \mathrm{mg} / \mathrm{kg}$ (ÖnerIyidoğan et al. 2013). Blood samples were obtained from the heart by cardiac puncture and was left for coagulation in room temperature and after that sent for centrifugation at $3000 \mathrm{rpm}$ for $20 \mathrm{~min}$ to obtain serum. The separated sera were stored at $-20^{\circ} \mathrm{C}$ for the following biochemical assessment. Following immediate laparotomy, terminal ileum of small intestine and liver were excised and rinsed with normal saline. Then, the terminal ileum was immersed in $10 \%$ buffered formalin solution for subsequent immunohistochemical assessment of GLP-1 immunoreactive cells. The liver was divided into two parts, the first part was preserved in $10 \%$ buffered formalin solution for histopathological examination. The second part was weighted and divided into two halves, one half was stored at $-20^{\circ} \mathrm{C}$ for detection of enzyme activities and the other half was preserved in RNAlater Stabilization Solution (ThermoFisher Scientific) at $4^{\circ} \mathrm{C}$ overnight before being stored at $-80^{\circ} \mathrm{C}$ until isolation of total RNA and subsequent real-time RT-PCR.

\section{Experimental induction of T2DM liver injury}

Experimental T2DM was induced by combination of HFD with low-dose of STZ according to a method designated previously (Reed et al. 2000; Chen et al. 2011). Briefly, rats were fed with HFD, which consisting of $58 \%$ fat, $17 \%$ carbohydrate, and $25 \%$ protein as a percentage of total $\mathrm{kcal}$ (Srinivasan et al. 2005). After 4 weeks of dietary management, these rats were fasted overnight and received a single intraperitoneal injection of STZ (35 mg/ $\mathrm{kg}$ dissolved in 0.3 $\mathrm{ml}$ citrate buffer solution at $\mathrm{pH} 4.5$ ). The rats were given $10 \%$ glucose solution $6 \mathrm{~h}$ after administration of STZ and continue for the next $24 \mathrm{~h}$ to overcome hypoglycemia induced by STZ. One week after STZ injection, only rats with fasting blood glucose (FBG) levels above $200 \mathrm{mg} / \mathrm{dl}$ were selected as diabetic rats then HFD and treatment with gallic acid and metformin were continued for another four weeks.

\section{Oral glucose tolerance test (OGTT)}

OGTT represents the body's efficacy in getting rid of glucose and is used as a basic measure for insulin resistance assessment (Guo et al. 2014). $48 \mathrm{~h}$ before rats were sacrificed, OGTT was performed for all experimental rats. After overnight (12 h) fasting, the rats administrated $2.0 \mathrm{~g} / \mathrm{kg}$ glucose ( $50 \%$ glucose solution) by oral gavage. Blood samples were taken from the tail vein of each rat and a glucometer (AccuChek Performa Meter, 140 Roche, Germany) was used to measure blood glucose levels at 0 (baseline), 15, 30, 60, and $120 \mathrm{~min}$ after administration of glucose.
Measurement of fasting blood glucose, insulin levels and Homeostatic Model Assessment of Insulin Resistance (HOMAIR)

The blood glucose levels (mg/dl) were measured using a glucose oxidase method (Contournext, Parsippany, USA). The levels of serum insulin were measured determined using the rat insulin ELISA kit purchased from Sun Red biological technology company, Shanghai, China according to Aughsteen et al. method (Aughsteen et al. 2006). HOMA-IR was calculated to determine insulin resistance as follows: fasting insulin levels $(\mu \mathrm{IU} / \mathrm{ml}) \times$ fasting glucose levels $(\mathrm{mg} / \mathrm{dl}) / 405$ (Muniyappa et al. 2009).

\section{Measurement of serum levels of lipid profile, liver enzymes and total bilirubin}

Total triglyceride (TG), total cholesterol (TC), low-density lipoprotein (LDL) and high-density lipoprotein (HDL) serum levels were measured using commercial kits bought from (SPINREACT, Spain). The activities of alanine transaminase (ALT) and aspartate transaminase (AST) were measured by quantitative colorimetric assay kit purchased from BioMérieux SA (France). Total serum bilirubin levels were assessed using commercial kits bought from Diamond Diagnostics company (USA).

\section{Measurement of serum levels of fetuin- $A$}

Serum fetuin-A concentrations were determined using commercial rat fetuin-A ELISA kits as directed by the manufacturer (Sun-Red biology and technology, Shanghai, China). The absorbance was read at the $450 \mathrm{~nm}$ wavelength.

\section{Measurement of antioxidant enzymes and oxidative stress marker in liver tissues}

The supernatant of liver homogenate used for detection of thiobarbituric acid reactive substance (MDA) activity using a spectrophotometer and the absorbance was read at $535 \mathrm{~nm}$ by a method of Ohkawa et al. (1979). In the prepared samples, reduced glutathione (GSH) was calculated according to the method defined by Jollow et al. (1974). Also, detection of superoxide dismutase (SOD) activity in the liver tissues was done according to Stevens et al. method (Stevens et al. 2000) and the absorbance was read by spectrophotometer at $420 \mathrm{~nm}$.

\section{Measurement of triglyceride (TG) and glycogen contents in} the liver tissues

The contents of liver TG were examined using the altered method stated by Kim et al. (2003). Briefly, $0.1 \mathrm{~g}$ frozen liver 
tissue was homogenized in chloroform/methanol (1 ml, 2:1 $\mathrm{vol} / \mathrm{vol}$ ) over ice. Homogenates were shaken overnight before adding $0.6 \% \mathrm{NaCl}$ and then the samples were centrifuged at $370 \times g$ for $10 \mathrm{~min}$ to separate phases. The TG-containing organic layer was separated and air-dried. The isolated lipids were resuspended in $250 \mathrm{ml}$ ethanol and colorimetric determination was performed in a spectrophotometer (SPECTRAmax PLUS384, Molecular Devices, Sunnyvale, CA, USA) at a wavelength of $505 \mathrm{~nm}$ or $490 \mathrm{~nm}$. Glycogen concentrations in the liver tissues were determined as described by Seifter and Dayton (1950). The optical density was read in a spectrophotometer at $620 \mathrm{~nm}$.

\section{Histopathological evaluation of the liver tissues}

Samples of the liver were stored in $10 \%$ formalin for $24 \mathrm{~h}$. Serial dilutions were carried out by ethyl alcohol cleared in xylene and embedded in paraffin wax to prepare $5 \mu \mathrm{m}$ thick sections stained with hematoxylin and eosin (H\&E) to examine the morphological changes. The stained sections were examined by light microscopy (binocular, Olympus). Histological pictures were picked up using digital camera (Canon, 5 mega pixels, $3.2 \times$ optical zoom).

\section{Immunohistochemical quantification of GLP-1 secreting} cells (L cells) in the terminal ileum

After the rats were sacrificed, $2 \mathrm{~cm}$ terminal ileum tissue was collected as previously described method of Kappe et al. (2014). All tissues were fixed in 4\% paraformaldehyde and processed for embedded in paraffin. At least 4 parts of each sample were sliced discontinuously, then used to assess the relative intestinal $\mathrm{L}$ cell with immunohistochemistry. After antigen repair and blockage of the endogenous peroxidase, sections were washed in PBS $3 \times 10 \mathrm{~min}$ and then incubated overnight $4^{\circ} \mathrm{C}$ with a rabbit antibody specific for GLP-1 (1:150, Catalog No. A1119, AB clonal Technology Company, USA). Tissue sections were washed in PBS $3 \times 10 \mathrm{~min}$ and incubated for $2 \mathrm{~h}$ at room temperature with the secondary antibody (Biotin-labeled goat anti-rabbit, BOSTER, SA1002, WuHan, China). Sections were washed in PBS $3 \times 10$ min then dyed with chromogenic substrate $\mathrm{DAB}$, and the positive cell number were observed under the microscope, then the results were expressed as the number of L cells per mucosal area (number $/ \mathrm{mm}^{2}$ ) from ten fields at $10 \times$ magnification by using Image J software (Zheng et al. 2017).

\section{Total RNA isolation and RT-PCR analysis}

Total RNA was extracted from frozen liver tissues with RNA TRIzol (Invitrogen, America), according to manufacturer instructions. RNA concentrations and purities were quantified using a Nanodrop ND-1000 spectrophotometer. Complementary DNA (cDNA) was synthesized from total RNA using the RNA PCR kit (TaKaRa, DaLian, China), according to manufacturer protocol. TransStart Top Green qPCR SuperMix kit was used for $\mathrm{qPCR}$ analysis (initial template denaturation at $95^{\circ} \mathrm{C}$ for $5 \mathrm{~s}$, followed by 40 cycles of $95^{\circ} \mathrm{C}$ for $30 \mathrm{~s}, 55^{\circ} \mathrm{C}$ for $30 \mathrm{~s}$, and $72^{\circ} \mathrm{C}$ for $30 \mathrm{~s}$ ). The cycle threshold values were used to calculate the normalized expression of GLUT-4, NF$\kappa \mathrm{B}, \mathrm{ERK} 1 / 2$, Wnt 1 and $\beta$-catenin against $\beta$-actin using the Q-Gene software. The sequences of the primer pairs are listed below: $\beta$-actin, 5'- CCTCATGCCATCCTGCGTCTG-3'/5' -TTGCTCGAAGTCTAGGGCAACATAG-3'; GLUT-4 5'-ACAATGTCTTGGCTGTGCTG3'/5' - TCCCACATACATAGGCACCA-3'; NF- $\mathrm{B}$, 5'-AAAAACGCATCCCAAGGTGC-3'/5'-AAGCTCAAGCCACCATACCC-3'; ERK $1 / 2$ 5' - GCTGACCCTGAGCACGACCA-3'/5'-CTGGTTCATCTGTCGGATCA-3'; Wnt 1 5' - CCCCGTGACCTCTCTGTGTATCAC-3'/5' TGAAGCCCAGGTGTGGTGGTT-3';' $\beta$-catenin, 5'-AAGTTCTTGGCTATTACGACA-3'/5' - ACAGCACCTTCAGCACTCT-3'. $\beta$-actin was used as the internal reference gene for normalization of gene expression levels. PCR was analyzed using the $2^{-\Delta \Delta \mathbf{C T}}$ cycle threshold method, as described previously (Livak and Schmittgen 2001).

\section{Statistical analysis and data interpretation}

Data were analyzed using IBM SPSS Statistics for Windows (Version 22.0. Armonk, NY, IBM Corp). Qualitative data were described using number and percent. Quantitative data were described using mean \pm SD for parametric data after testing normality using Kolmogorov-Smirnov test. Significance of the obtained results was judged at the $p<0.05$. All graphic representations of the data were performed with Microsoft Excel for Windows (Microsoft Inc., USA). ANOVA with repeated measures was used to analyses blood glucose level at different time points of OGTT. Total area under the curve (AUC) was calculated to evaluate blood glucose levels after exogenous glucose load. One Way ANOVA test was used to compare more than 2 independent groups with post hoc Tukey test to detect pair-wise comparison. Pearson correlation coefficient test was used to correlate different parameters.

\section{Results}

Effect of gallic acid on OGTT in T2DM

For all experimental groups, time-dependent changes in blood glucose levels were done during the OGTT (0-120 min) and presented in Figure 1. A significant interaction 

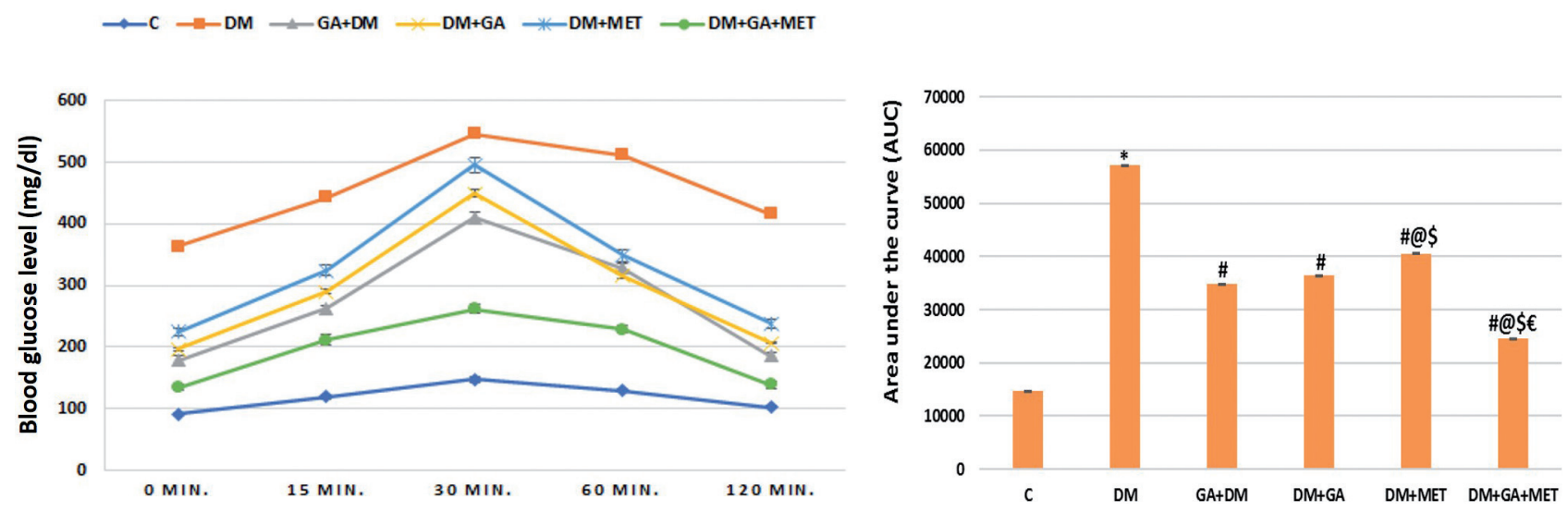

Figure 1. Effects of gallic acid in all experimental groups on OGTT. Line graph showing mean oral glucose tolerance test (OGTT) and area under the curve (AUC) of all experimental groups. All parameters described as mean $\pm \mathrm{SD}(n=10)$. Glucose response over time, was analyzed by ANOVA with repeated measurements. ${ }^{*} p<0.001 v$ s. Control group; ${ }^{\#} p<0.001 v s$. DM group; ${ }^{@} p<0.001 v s . \mathrm{GA}+\mathrm{DM}$ group; ${ }^{\$} p<0.001 v$ s. DM+GA group; ${ }^{€} p<0.001$ vs. DM+MET group. One-way ANOVA with post hoc Tukey test. C, Control group; $\mathrm{DM}$, untreated diabetic group; GA+DM, diabetic group pretreated with gallic acid; DM+GA, diabetic group treated with gallic acid; $\mathrm{DM}+\mathrm{MET}$, diabetic rats treated with metformin; $\mathrm{DM}+\mathrm{GA}+\mathrm{MET}$, diabetic group treated with gallic acid + metformin.

between time and groups was revealed by the ANOVA with repeated measures $(\mathrm{F}=956.95 ; p=0.001)$, 99\% of OGTT is influenced by the interaction between measurement time and studied groups. Statistical analysis of the AUC also showed that blood glucose levels in the untreated diabetic rats were significantly elevated relative to the normal group $(p<0.001)$. The AUCs of the group treated with combination therapy appeared to be slightly lower than those of the other monotherapy-administering groups $(p<0.001)$.

Effect of gallic acid on the weight of the body and liver and liver weight/body weight ratio

Data presented in Table 1 revealed a significant decrease in the body weight of the untreated DM group when compared to control ones $(p \leq 0.001)$. However, administration of gallic acid and metformin either individually or in combination to the diabetic rats induce significant increase in the body weight in comparison to the untreated DM group $(p \leq 0.001)$. On the other hand, the liver weight and its ratio with body weight were significantly increased in the untreated DM group when compared to the Control group ( $p \leq$ $0.001)$. These two parameters were significantly decreased in the diabetic rats treated with gallic acid and metformin when compared to the untreated DM one $(p \leq 0.001)$. However, the diabetic rats that received combined treatment showed a remarkable improvement in the weight of the body and liver and liver weight/body weight ratio relative to the other treated groups $(p \leq 0.001)$.

\section{Effect of gallic acid on the levels of fasting blood glucose, insulin, and HOMA-IR}

Our results presented in Table 2 revealed a significant increase in the FBG level $(p<0.001)$ accompanied with a significant decrease in the serum insulin level $(p<0.001)$ of the untreated DM group relative to the Control group. However, administration of gallic acid to the diabetic rats

Table 1. The effect of gallic acid on the weights of body (BW) and liver (LW) and liver weight/body weight ratio in all experimental groups

\begin{tabular}{|c|c|c|c|c|c|c|}
\hline & Control & $\mathrm{DM}$ & $\mathrm{GA}+\mathrm{DM}$ & $\mathrm{DM}+\mathrm{GA}$ & $\mathrm{DM}+\mathrm{MET}$ & $\mathrm{DM}+\mathrm{GA}+\mathrm{MET}$ \\
\hline BW (g) & $285.43 \pm 6.9$ & $199.21 \pm 18.8^{\star}$ & $247.57 \pm 25.71^{\#}$ & $239.44 \pm 12.1^{\# @}$ & $218.62 \pm 9.9^{\# @ \$}$ & $275.77 \pm 9.72^{\# @ \$ €}$ \\
\hline LW $(g)$ & $6.89 \pm 0.12$ & $13.84 \pm 2.4^{*}$ & $8.23 \pm 2.12^{\#}$ & $8.99 \pm 0.27^{\# @}$ & $10.99 \pm 0.37^{\# @ \$}$ & $7.52 \pm 0.06^{\# @ \$ €}$ \\
\hline LW/BW (\%) & $2.41 \pm 0.04$ & $6.95 \pm 1.1^{*}$ & $3.32 \pm 0.8^{\#}$ & $3.75 \pm 1.03^{\# @}$ & $5.02 \pm 0.24^{\# @ \$}$ & $2.73 \pm 0.37^{\# @ \$ €}$ \\
\hline
\end{tabular}

Data are mean $\pm \mathrm{SD}(n=10) .{ }^{\star} p<0.001 v s$. Control group, ${ }^{*} p<0.001 v s . \mathrm{DM}$ group, ${ }^{@} p<0.001 v s$. GA+DM group, ${ }^{\$} p<0.001 v s$. $\mathrm{DM}+\mathrm{GA}$ group, ${ }^{€} p<0.001$ vs. DM+MET group (ANOVA with post hoc Tukey test). Control, Control group; DM, untreated diabetic group; $\mathrm{GA}+\mathrm{DM}$, diabetic group pretreated with gallic acid; DM+GA, diabetic group treated with gallic acid; DM+MET, diabetic group treated with metformin, DM+GA+MET, diabetic group treated with gallic acid + metformin. 
Table 2. Effect of gallic acid on the blood glucose, serum levels of insulin and HOMA-IR in all experimental groups

\begin{tabular}{lccrrrr}
\hline & Control & DM & GA+DM & DM+GA & \multicolumn{1}{c}{ DM+MET } & DM+GA+MET \\
\hline Blood glucose $(\mathrm{mg} / \mathrm{dl})$ & $87.90 \pm 6.31$ & $382.9 \pm 19.69^{*}$ & $135.70 \pm 5.73^{\#}$ & $144.30 \pm 4.14^{\# @}$ & $156.77 \pm 6.20^{\# @ \$}$ & $102.59 \pm 8.81^{\# @ \$ €}$ \\
Insulin $(\mu \mathrm{IU} / \mathrm{ml})$ & $11.55 \pm 0.46$ & $6.054 \pm 0.151^{*}$ & $8.29 \pm 0.24^{\#}$ & $7.64 \pm 0.09^{\# @}$ & $6.76 \pm 0.158^{\# @ \$}$ & $9.62 \pm 0.36^{\# @ \$ €}$ \\
HOMA-IR & $2.51 \pm 0.19$ & $5.75 \pm 0.25^{*}$ & $2.78 \pm 0.23^{\#}$ & $2.72 \pm 0.97^{\# @}$ & $2.61 \pm 0.73^{\# @ \$}$ & $2.43 \pm 0.11^{\# @ \$ €}$ \\
\hline
\end{tabular}

Data are mean \pm SD $(n=10) .{ }^{\star} p<0.001$ vs. Control group, ${ }^{\#} p<0.001$ vs. DM group, ${ }^{@} p<0.001 v s$. GA + DM group, ${ }^{\$} p<0.001 v s$. $\mathrm{DM}+\mathrm{GA}$ group, ${ }^{€} p<0.001 v s$. DM+MET group (ANOVA with post hoc Tukey test). For abbreviations, see Table 1.

resulted in a significant decrease in the FBG level $(p<0.001)$ together with a significant elevation in the level of insulin $(p<0.001)$ when compared to the untreated DM group. This improvement in the level of both FBG and serum insulin with gallic acid was reflected on the insulin sensitivity index as detected by HOMA-IR in Table 2 . However, the beneficial effects were very prominent in the combined treated rats when compared to the other treated ones.

Effect of gallic acid on the serum levels of liver enzymes and bilirubin and lipid profile

The results shown in Table 3 presented a significant elevation in the serum level of ALT, AST, total bilirubin together with a significant increase in TG, total cholesterol, LDL associated with a significant decrease in the level of HDL in the untreated DM group in comparison to the control one $(p \leq 0.001)$. However, administration of gallic acid significantly improved these diabetic effects on these parameters. Among of all treated groups, the diabetic rats received combined treatment of gallic acid and metformin displayed maximum improvement of these liver enzymes and functions parameters.

\section{Effect of gallic acid on the serum levels of fetuin- $A$}

The serum level of fetuin-A was elevated significantly in the untreated DM group when compared with the Con-

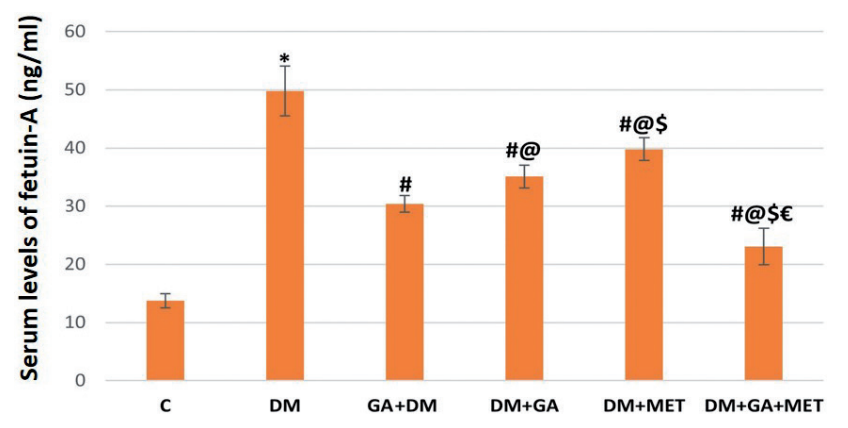

Figure 2. Bar chart showing mean serum level fetuin-A (ng/ml) in all experimental groups. All parameters described as mean \pm SD $(n=10) .{ }^{\star} p<0.001 v s$. Control group; ${ }^{\#} p<0.001 v s$. DM group; ${ }^{\circledR} p<0.001$ vs. GA+DM group; ${ }^{\$} p<0.001$ vs. DM+GA group; ${ }^{€} p<$ 0.001 vs. DM+MET group. One-way ANOVA with post hoc Tukey test. For abbreviations, see Fig. 1.

trol one $(p<0.001)$. On the other hand, administration of gallic acid to the diabetic rats resulted in a significant decrease in the serum level of fetuin-A when compared to the untreated DM group $(p<0.001)$ as shown in Figure 2. However, the observed effect was very prominent in the combined treated group when compared to the other treated ones. The diabetic rats administered gallic acid alone showed a marked improvement in the serum level of fetuin-A relative to the diabetic rats treated only with metformin.

Table 3. Effect of gallic acid on the serum levels of liver enzymes (AST and ALT), total bilirubin and lipid profile in all experimental groups

\begin{tabular}{lcccccl}
\hline & Control & DM & GA+DM & DM+GA & DM+MET & DM+GA+MET \\
\hline ALT (U/l) & $50.50 \pm 1.08$ & $140.30 \pm 2.2^{*}$ & $82.1 \pm 0.9^{\#}$ & $88.0 \pm 2.16^{\# @}$ & $102.4 \pm 4.88^{\# @ \$}$ & $75.80 \pm 2.39^{\# @ \$ €}$ \\
AST (U/l) & $31.60 \pm 1.8$ & $89.0 \pm 5.08^{*}$ & $51.30 \pm 0.8^{\#}$ & $55.4 \pm 1.8^{\# @}$ & $62.2 \pm 1.5^{\# @ \$}$ & $47.60 \pm 0.7^{\# @ \$ €}$ \\
Bilirubin (mg/dl) & $0.439 \pm 0.03$ & $0.952 \pm 0.03^{*}$ & $0.622 \pm 0.02^{\#}$ & $0.727 \pm 0.03^{\# @}$ & $0.818 \pm 0.03^{\# @ \$}$ & $0.579 \pm 0.01^{\# @ \$ €}$ \\
TC (mg/dl) & $138.0 \pm 2.8$ & $247.3 \pm 3.6^{*}$ & $183.20 \pm 3.5^{\#}$ & $196.2 \pm 2.5^{\# @}$ & $211.8 \pm 6.1^{\# @ \$}$ & $168.5 \pm 3.5^{\# @ \$ €}$ \\
TG (mg/dl) & $57.6 \pm 2.2$ & $216.2 \pm 3.4^{*}$ & $110.73 \pm 6.1^{\#}$ & $125.03 \pm 7.9^{\# @}$ & $167.9 \pm 3.9^{\# @ \$}$ & $74.38 \pm 4.8^{\# @ \$ €}$ \\
HDL (mg/dl) & $50.60 \pm 2.6$ & $20.20 \pm 3.05^{*}$ & $36.20 \pm 0.8^{\#}$ & $32.50 \pm 0.8^{\# @}$ & $28.8 \pm 1.2^{\# @ \$}$ & $41.70 \pm 1.9^{\# @ \$ €}$ \\
LDL (mg/dl) & $75.85 \pm 2.01$ & $187.82 \pm 12.8^{*}$ & $113.42 \pm 3.8^{\#}$ & $126.50 \pm 1.5^{\# @}$ & $144.08 \pm 6.3^{\# @ \$}$ & $96.52 \pm 3.5^{\# @ \$ €}$ \\
\hline
\end{tabular}

Data are mean $\pm \mathrm{SD}(n=10) .{ }^{\star} p<0.001$ vs. Control group, ${ }^{\#} p<0.001 v s$. DM group, ${ }^{@} p<0.001$ vs. GA+DM group, ${ }^{\$} p<0.001 v s . \mathrm{DM}+\mathrm{GA}$ group, ${ }^{€} p<0.001$ vs. DM+MET group (ANOVA with post hoc Tukey test). ALT, alanine transaminase; AST, aspartate transaminase; TC, total cholesterol; TG, total triglyceride; HDL, high-density lipoprotein; LDL, low density lipoprotein. For more abbreviations, see Table 1. 
A

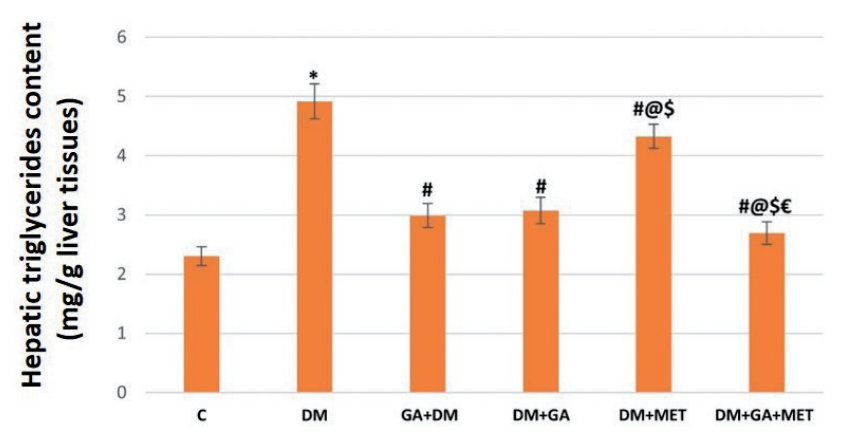

B

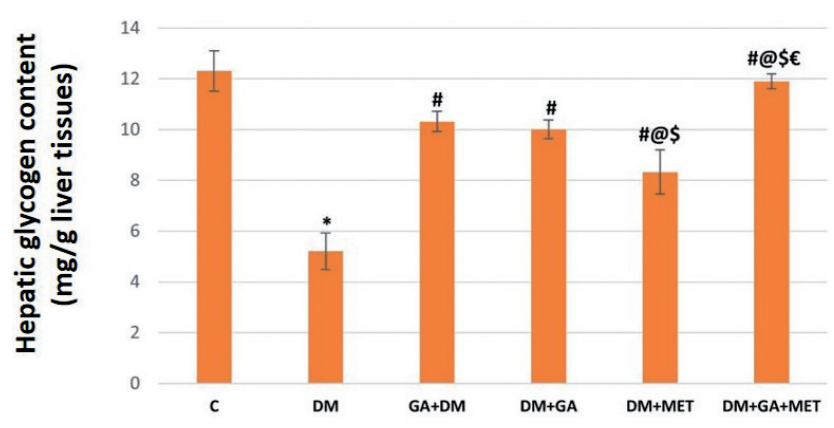

Figure 3. Effect of gallic acid on the hepatic contents of triglycerides (A) and glycogen (B) in all experimental groups. All parameters described as mean $\pm \mathrm{SD}(n=10) .{ }^{*} p<0.001 v s$. Control group; ${ }^{*} p<0.001 v s$. DM group; ${ }^{@} p<0.001 v s$. GA+DM group; ${ }^{\$} p<0.001 v s$. $\mathrm{DM}+\mathrm{GA}$ group; ${ }^{€} p<0.001$ vs. DM+MET group. One-way ANOVA with post hoc Tukey test. For abbreviations, see Fig. 1.

\section{Effect of gallic acid on the hepatic TG content}

The results shown in Figure 3A presented a significant elevation in the untreated DM rats' hepatic TG in comparison to the Control group $(p<0.001)$. However, all treated groups either single or combined exhibited a significant improvement in this parameter relative to the untreated DM group $(p<0.001)$. However, the most prominent improvement of the hepatic TG content was observed in the combined treated group relative to the monotherapy groups. Gallic acid administrated diabetic rats showed a marked improvement in the hepatic TG when compared to the results of diabetic rats treated only with metformin.

\section{Effect of gallic acid on the hepatic glycogen content}

Our results presented in Figure 3B revealed a significant decrease in the glycogen content in the liver tissue of the untreated DM group relative to Control one $(p<0.001)$. On the contrary, administration of gallic acid to the diabetic rats resulted in a significant increase in the level of glycogen content when compared to the untreated DM group $(p<$ 0.001 ). However, the observed effect was very prominent in the combined treated rats when compared to the other treated ones. The diabetic rats treated gallic acid alone showed a marked enhancement in the hepatic glycogen
A

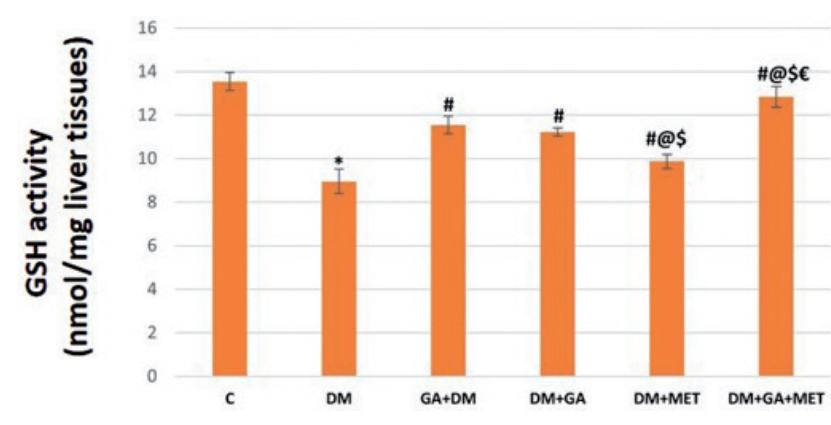

C

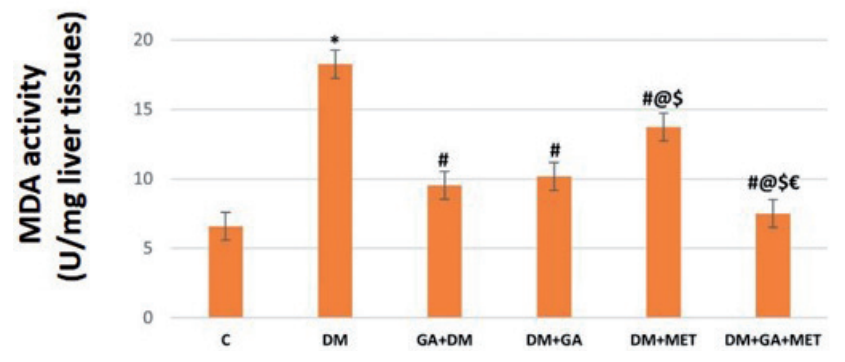

B

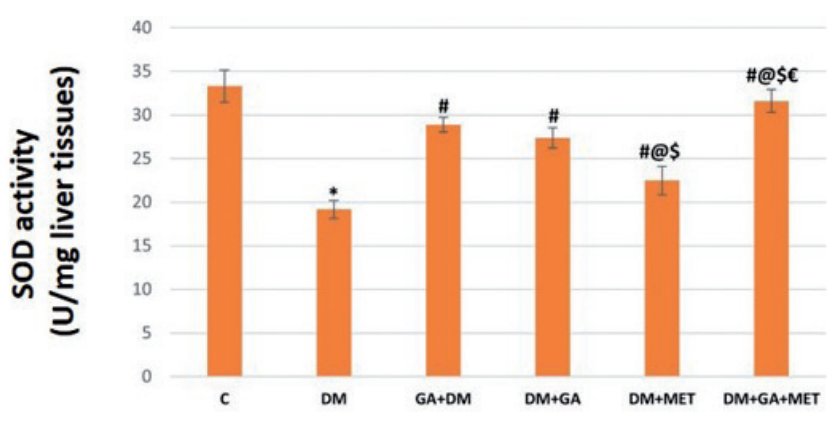

Figure 4. Effect of gallic acid on the hepatic oxidative stress markers and antioxidants' activities in all experimental groups. Effect of gallic acid on the hepatic activities of reduced glutathione (GSH; A), superoxide dismutase (SOD; B) and malonaldehyde (MDA; C). All parameters described as mean $\pm \mathrm{SD}(n=10) .{ }^{*} p<0.001 v s$. Control group; ${ }^{\#} p<0.001$ vs. DM group; ${ }^{@} p<0.001$ vs. GA+DM group; ${ }^{\$} p<0.001$ vs. DM+GA group; ${ }^{€} p<0.001$ vs. DM+MET group. One-way ANOVA with post hoc Tukey test. For abbreviations, see Fig. 1. 
A

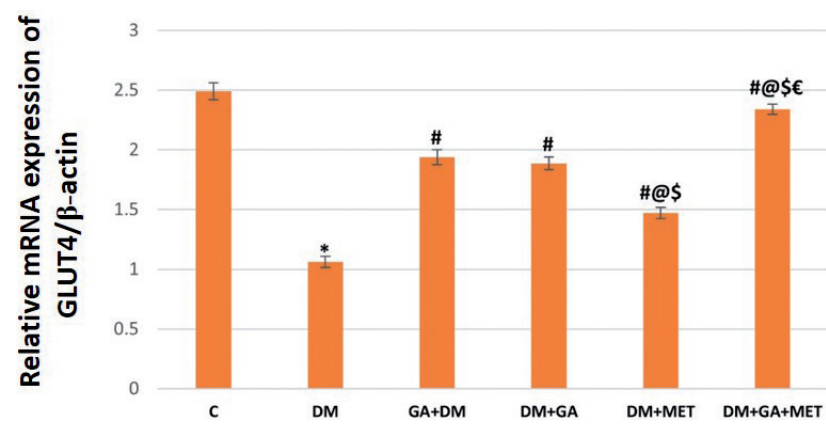

C

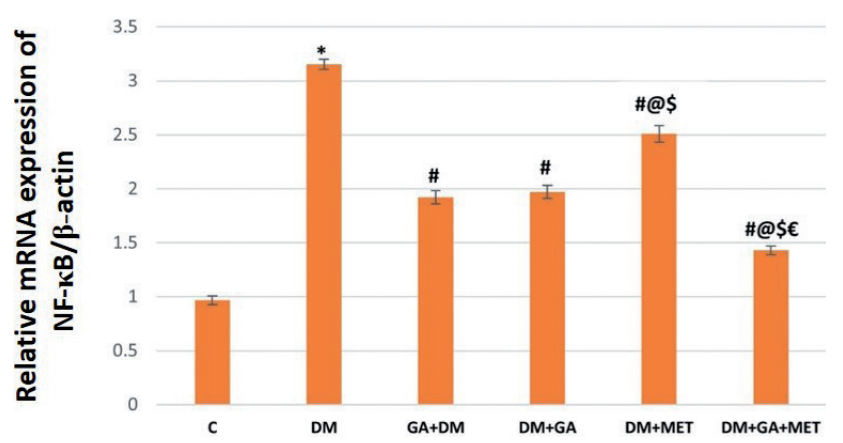

E

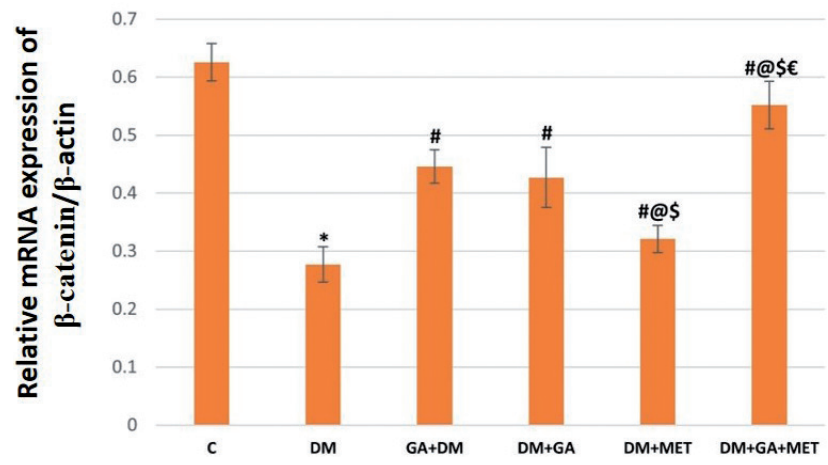

content relative to the results of diabetic rats treated only with metformin.

Effect of gallic acid on the hepatic antioxidant enzymes and oxidative stress marker

The data presented in Figure 4 showed a significant decline in the levels of GSH and SOD in the liver tissue of the untreated DM group $(p<0.001)$ with significant elevation in the level of MDA $(p<0.001)$ in comparison with the control results. All treated groups revealed that, the activity of antioxidants enzymes was significantly increased $(p<0.001)$ together with a significant decrease in the level of MDA $(p<0.001)$ when compared with the untreated DM group. However, the
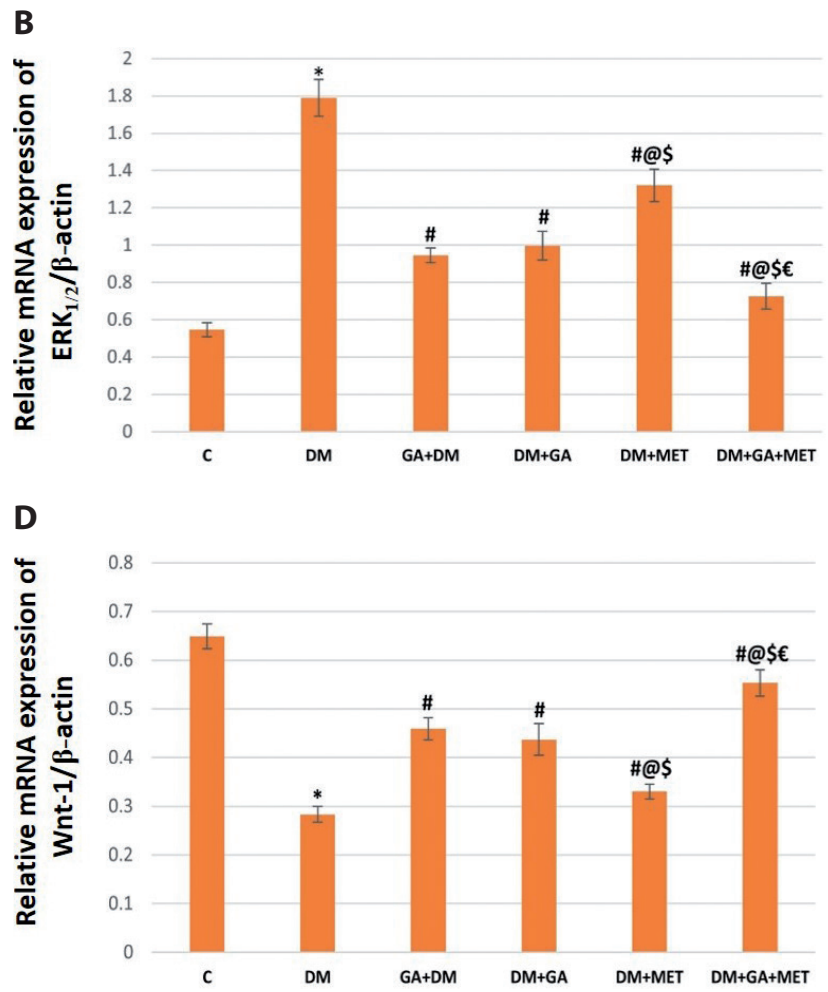

Figure 5. Effect of gallic acid on the hepatic mRNA expression of GLUT-4 (A), ERK $_{1 / 2}$ (B), NF- $\mathrm{BB}$ (C) Wnt1 (D) and $\beta$-catenin (E) in all experimental groups. All parameters described as mean $\pm \mathrm{SD}$ $(n=10) .{ }^{*} p<0.001$ vs. Control group; ${ }^{\#} p<0.001 v s$. DM group; ${ }^{\circledR} p<0.001 v s$. GA+DM group; ${ }^{\$} p<0.001 v s$. DM+GA group; ${ }^{€} p<$ $0.001 v s$. DM+MET group. One-way ANOVA with post hoc Tukey test. For abbreviations, see Fig. 1.

combined treated group showed the most prominent effect relative to the other treated diabetic groups. The diabetic rats treated with gallic acid showed a marked enhancement in the antioxidant enzymes' activities in favor of oxidative stress marker when compared to the results of the diabetic rats treated with metformin alone.

Effect of gallic acid on the hepatic expression of GLUT-4 mRNA

The data presented in Figure 5A discovered a significant decrease in the mRNA levels of GLUT- 4 in the liver of the untreated diabetic rats when compared to the control result. However, the diabetic rats which received combined treatment revealed a marked increase in the expression of GLUT- 
4 when compared with the untreated diabetic rats. Gallic acid administrated diabetic rats showed a marked increase in the hepatic expression of this gene when compared to the results of diabetic rats treated only with metformin.

Effect of gallic acid on the hepatic expression of $E R K_{1 / 2}$ and $N F-\kappa B$ mRNA

The results shown in Figure 5B and $C$ revealed a significant increase in the mRNA levels of both $\mathrm{ERK}_{1 / 2}$ and NF- $\mathrm{KB}$ in the untreated diabetic rats' liver when compared to the control result. On the other hand, the diabetic rats treated with gallic acid either alone or combined with metformin revealed marked decline in the expression of $\mathrm{ERK}_{1 / 2}$ and NF$\kappa \mathrm{B}$ when compared with the untreated diabetic rats. Gallic acid administrated diabetic rats showed a marked decrease in the hepatic expression of both genes when compared to the results of diabetic rats treated only with metformin.

\section{Effect of gallic acid on the hepatic expression of Wnt 1 and $\beta$-catenin mRNA}

The data presented in Figure 5D and E revealed a significant decrease in the mRNA levels of Wnt1 and $\beta$-catenin in the liver tissue of untreated diabetic rats when compared to the Control group. Meanwhile, the diabetic rats treated with gallic acid either alone or combined with metformin revealed marked increase in the expression of both genes when compared with the untreated diabetic rats. However, gallic acid administrated diabetic rats showed a marked
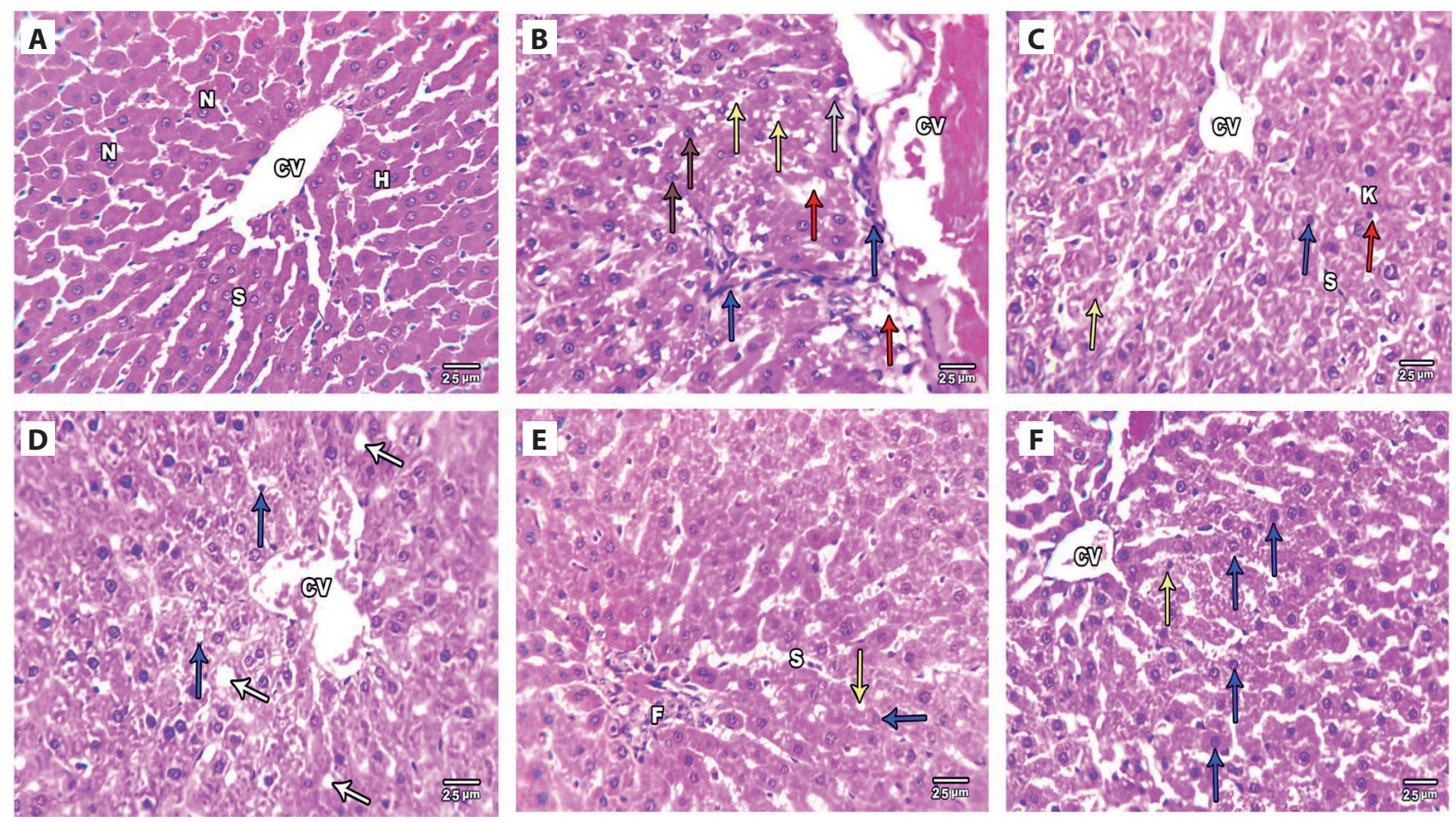

Figure 6. Histopathological assessment of liver tissue. A. Liver specimens of normal Control group showing normal liver architecture, central vein $(\mathrm{CV})$, normal hepatocytes $(\mathrm{H})$ having acidophilic cytoplasm and rounded central vesicular euchromatic nuclei $(\mathrm{N})$ with well-defined nucleoli and hepatocytes plates are separated by thin-walled blood sinusoids lined by flat endothelial cells (S). B. Liver specimens of DM group showing dilated central vein (CV) with damaged lining endothelium and surrounded by inflammatory cell infiltrates (blue arrows), focal hepatocyte necrosis (red arrows), pyknotic nuclei (brown arrows), fatty globules in hepatocytes (yellow arrow), sporadic (apoptotic) cells with dark stained acidophilic cytoplasm and small dark (pyknotic) nuclei (gray arrows). C. Liver specimens of GA+DM group showing normal central vein (CV) with intact lining endothelium, focal hepatocyte necrosis, pyknotic nuclei (blue arrows), fatty globules in hepatocytes (red arrows), blood sinusoids (S), Von Kupffer (K) cells and few apoptotic cells with dark stained acidophilic cytoplasm and small dark (pyknotic) nuclei (yellow arrows). D. Liver specimens of DM+GA group showing dilated central vein (CV) with damaged lining endothelium, focal hepatocyte necrosis with pyknotic nuclei (blue arrows), fatty globules in hepatocytes (white arrows). E. Liver specimens of DM+MET group showing damaged lining endothelium of blood sinusoids (S), focal hepatocyte necrosis with pyknotic nuclei (blue arrows), fatty globules in hepatocytes (yellow arrows), blood sinusoids (S) with interstitial inflammatory infiltrates (F). F. Liver specimens of DM+GA+MET group showing near normal liver architecture, normal central vein, few pyknotic nuclei (yellow arrows), normal hepatocytes having acidophilic cytoplasm and rounded central vesicular euchromatic nuclei with well-defined nucleoli (blue arrows) (400×, H\&E). For color Figure, see on-line version of the manuscript. 
Table 4. Comparison of GLP-1 cell count and percentage area (\% area) in the terminal ileum among all experimental groups

\begin{tabular}{|c|c|c|c|c|c|c|}
\hline & Control & $\mathrm{DM}$ & $\mathrm{GA}+\mathrm{DM}$ & $\mathrm{DM}+\mathrm{GA}$ & $\mathrm{DM}+\mathrm{MET}$ & $\mathrm{DM}+\mathrm{GA}+\mathrm{MET}$ \\
\hline Cell count (cells $\left./ \mathrm{mm}^{2}\right)$ & $33.30 \pm 1.83$ & $7.10 \pm 0.73^{\star}$ & $24.70 \pm 0.823^{\#}$ & $20.0 \pm 1.05^{\# @}$ & $16.80 \pm 0.918^{\# @ \$}$ & $29.20 \pm 1.47^{\# @ \$ €}$ \\
\hline Area (\%) & $1.01 \pm 0.01$ & $0.140 \pm 0.01^{\star}$ & $0.782 \pm 0.08^{\#}$ & $0.663 \pm 0.01^{\# @}$ & $0.275 \pm 0.008^{\# @ \$}$ & $0.936 \pm 0.02^{\# @ \$ €}$ \\
\hline
\end{tabular}

Data are mean $\pm \mathrm{SD} .{ }^{*} p<0.001 v s$. Control group, ${ }^{*} p<0.001 v s$. DM group, ${ }^{@} p<0.001 v s$. GA+DM group, ${ }^{\$} p<0.001 v s . \mathrm{DM}+\mathrm{GA}$ group, ${ }^{€} p<0.001$ vs. DM+MET group (ANOVA with post hoc Tukey test). For abbreviations, see Table 1.

increase in the hepatic expression of Wnt1 and $\beta$-catenin genes when compared to the results of diabetic rats treated only with metformin.

Effect of gallic acid on the histopathological changes in the liver of all experimental rats

The histopathological analysis of the liver revealed dilated central vein with damaged lining endothelium which surrounded by inflammatory cell infiltrates, focal hepatocyte necrosis, fatty globules in hepatocytes and apoptotic cells in the untreated diabetic group (Fig. 6B). Administration of gallic acid and metformin either individually or combined to the diabetic rats resulted in marked restore of these histopathological changes (Fig. 6C-F). However, the combined treated group showed almost no damages and near normal liver architecture were found (Fig. 6F).

Effect of gallic acid on the expression of GLP-1 secreting cell in the terminal ileum

Figure 7 and Table 4 represent the immunohistochemical expression of GLP-1 secreting cells (L cells) in the terminal ileum of all experimental groups. Figure 7 showed presence of GLP-1-immunopositive cells between the epithelial cells in the intestinal crypts. The expression of L cells was significantly decreased in the untreated DM group when compared to the control one $(p \leq 0.001)$. However, the expression of these cells was significantly increased in all treated rats when compared to the untreated DM group ( $p \leq 0.001)$. In comparison to the
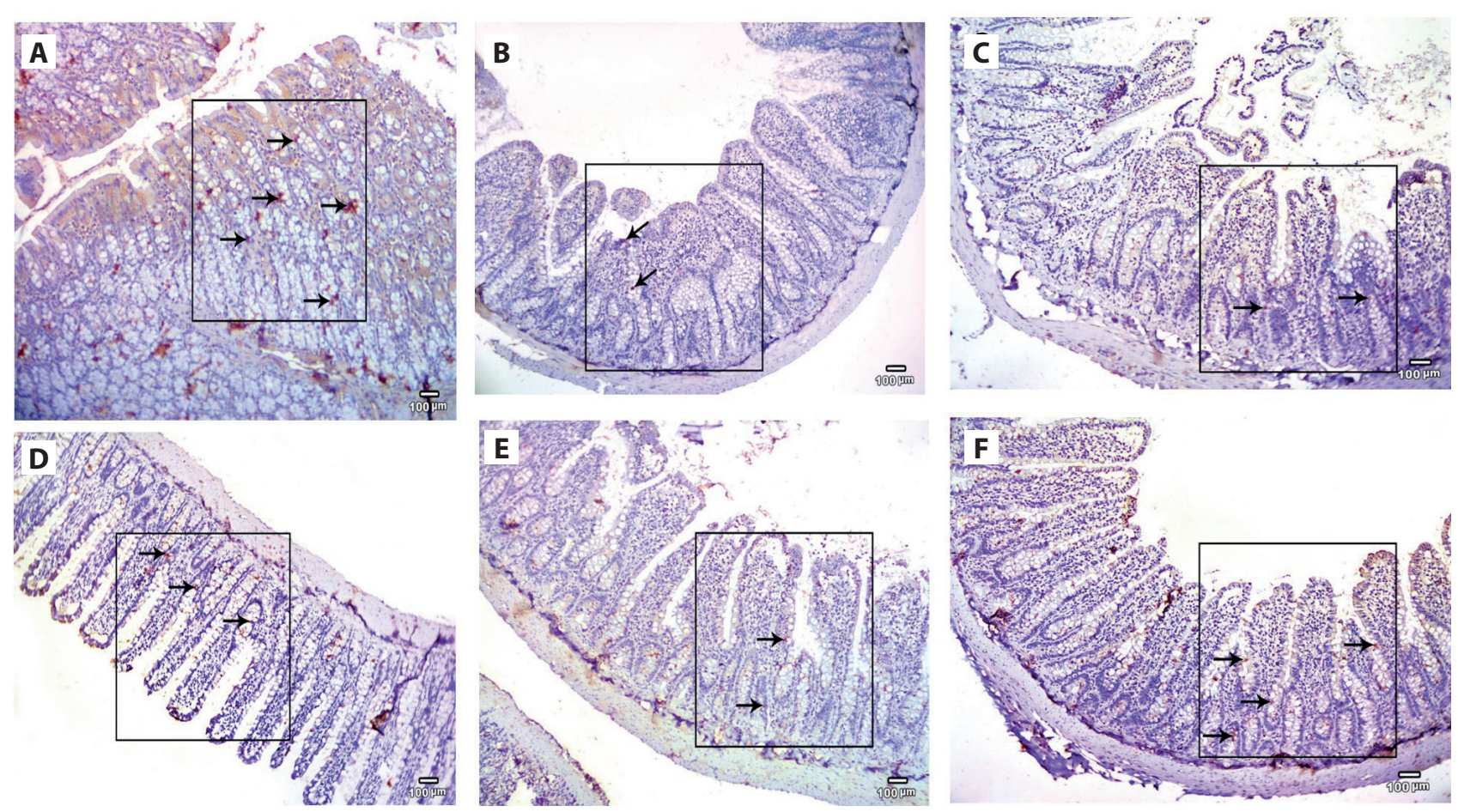

Figure 7. Immunohistochemical assessment of GLP-1 immunoreactive cells in the terminal ileum. A. Terminal ileum of normal Control group showing high number of GLP-1-positive cells (arrows). B. Terminal ileum of DM group showing very low number of GLP-1 positive cells. C. Terminal ileum of GA+DM group showing moderate number of GLP-1 positive cells. D. Terminal ileum of DM+GA group showing moderate number of GLP-1 positive cells. E. Terminal ileum of DM+MET group showing mild number of GLP-1 positive cells. F. Terminal ileum of DM+GA+MET group showing high number of GLP-1 positive cells $(100 \times)$. 
A

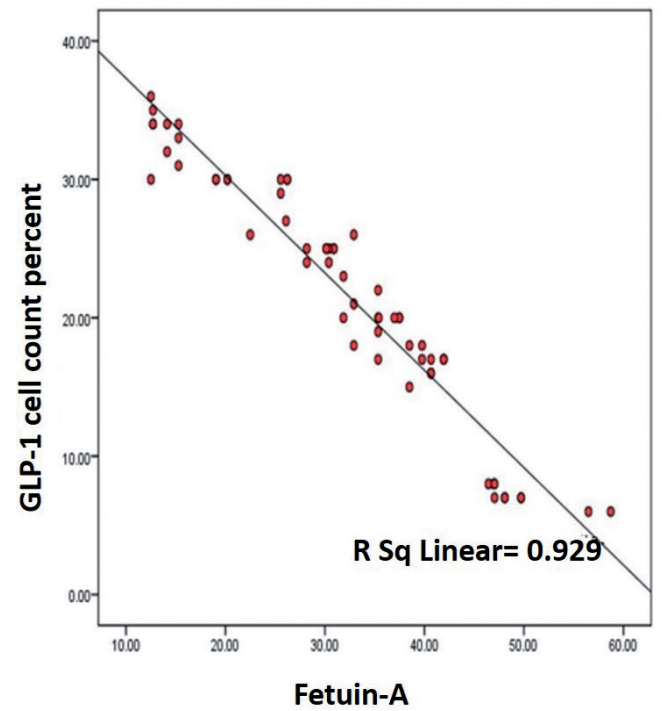

B

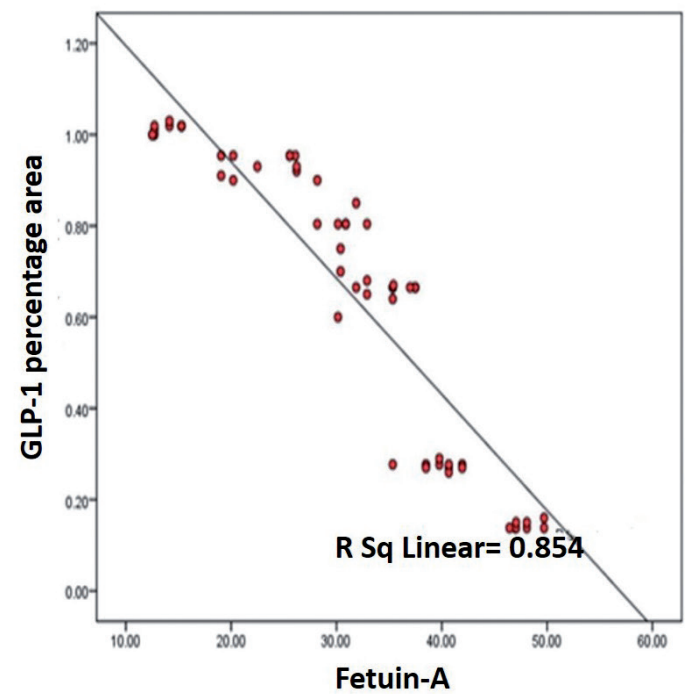

Figure 8. Correlation between fetuinA level and GLP-1 secreting cells count (A), between fetuinA level and GLP-1 expression percent area (B). single treated groups, the combined treated one showed the most beneficial effect $(p \leq 0.001)$. In addition, the diabetic rats that administered gallic acid alone showed a marked increase in the expression of GLP-1 immuno-reactive cells relative to the results of diabetic rats treated only with metformin.

Effect of gallic acid on the correlation between the serum levels of fetuin-A and the expression of GLP-1 secreting cells

The data found in Table 5 and Figure 8 represent the Pearson correlation analysis between serum level of fetuin-A and GLP-1 immunoreactive cells. Our result showed a negative correlation between fetuin-A serum level and GLP-1 secreting cells count $(\mathrm{r}=-0.973, p<0.001)$ and GLP-1 expression percent area $(r=-0.963, p<0.001)$ in all experimental groups.

\section{Discussion}

In the present study, we confirmed the therapeutic effect of gallic acid on the diabetic liver injury by regulating glucose and lipid metabolism disorder and alleviating oxidative stress in a rat model of T2DM. In addition, gallic acid increased insulin sensitivity by decreasing serum level of fetuin-A and improves glucose uptake in the insulin dependent organs such as liver through increase the expression of GLP-1 secreting cells in the terminal ileum together with an increase in the expression of GLUT4, Wnt1 and $\beta$-catenin mRNA levels in hepatocytes. Moreover, gallic acid reduced the hepatic TG accumulation while increased its glycogen content which associated with suppression of $\mathrm{ERK}_{1 / 2} / \mathrm{NF}-\kappa \mathrm{B}$ signaling pathway. Also, according to our result we found that treat- ment of diabetic rats with gallic acid alone either before or after induction of T2DM exhibited more potent effect than treatment only with metformin. However, the animals that received gallic acid before injection with STZ showed an improvement in all studied parameters more than the group treated with gallic acid alone after injection with STZ.

The results of the present study revealed a significant increase in the fasting blood glucose and HOMA-IR along with a significant decrease in the serum insulin level. These all results are in agreement with Silvares et al. (2016). A study performed by Feng et al. (2017) demonstrated that serum insulin level was elevated in the early stage of T2DM, playing a compensatory role in response to insulin resistance. However, the level of insulin is gradually decreased in parallel with the progression of diabetes since massive destruction occurs in the pancreatic $\beta$ cells. Administration of gallic acid ameliorates all these changes suggesting its hypoglycemic property together with improvement of insulin sensitivity which evaluated by HOMA-IR this could be explained in our results by its enhancing effect on GLUT4 mRNA expression level in the liver tissues. The expression of GLUT4 in the liver is controversial, however Bhattacharya and his colleagues demonstrated that,

Table 5. Correlation between serum level of fetuin A and GLP-1 cells in the terminal ileum for all studied groups

\begin{tabular}{lcc}
\hline & \multicolumn{2}{c}{ Fetuin-A } \\
\cline { 2 - 3 } & $\mathrm{r}$ & $p$ \\
\hline GLP 1 (Cell count $\left./ \mathrm{mm}^{2}\right)$ & $-0.973^{\star *}$ & $<0.0001^{*}$ \\
GLP 1 (\% area) & $-0.963^{\star *}$ & $<0.001^{\star}$ \\
\hline
\end{tabular}

$\mathrm{r}$, Spearman correlation coefficient; ${ }^{*}$ statistically significant. 
glucose facilitated its delivery in the hepatocytes through an increase the expression of GLUT4 and via the synthesis of nitric oxide which had an important role for insulin synthesis in the presence of glucose in the liver cells (Bhattacharya et al. 2013). Furthermore, Nyoman et al. (2017) reported that the expression of GLUT4 in the liver in higher than its level in the muscle in hyperglycemic condition.

Our data showed that in the untreated DM group, the body weights of the rats were reduced; these outcomes are consistent with those obtained by Zeng et al. (2019), they attributed the decline in body weight to the degradation of tissue protein in diabetic rats as a source of energy. Furthermore, this decrease in body weight can contribute to insulin deficiency, which prevents the entry of glucose into the cell, increasing its percentage in the blood and excretion of this glucose in the urine, leading to dehydration, resulting in decreased body weight (Sujithra et al. 2018). In addition, we showed a substantial increase in the weight and ratio of the liver of untreated diabetic rats in relation to body weight, which can be explained by an increase in hepatic TG material contents (Vergès 2015). Along with these alterations, increased serum levels of liver enzymes (AST, ALT), total bilirubin, TG, cholesterol, LDL together with reduction in the level of HDL were also noticed in the untreated DM group. These findings are consistent with those obtained by Huang et al. (2017) who attributed the rise in aminotransferase levels to the cellular damage caused by STZ exposure in the hepatocytes. Determination of serum bilirubin as a sensitive predictor for liver function assessment and any serum abnormality imply impairment of hepatocellular function (Mohamed et al. 2016). In addition, lipid profile abnormalities in T2DM may be related to increased absorption and endogenous hepatic output of TGs following ingestion of HFD with a decrease in peripheral tissue uptake (Pillai Subramanian 2018). Furthermore, insulin deficiency and resistance reduce the activity of lipoprotein lipase, a crucial enzyme in the degradation and removal of TGs from circulation (Naidu et al. 2015). Also, it may be due to the increased activity of insulin sensitive 3-hydroxy-3-methyl-glutaryl-coenzyme A reductase (HMG-CoA reductase); the rate-controlling enzyme of the mevalonate pathway which is the metabolic pathway that ended by synthesis of cholesterol (Pillai Subramanian 2018). Obviously, as detected by decreasing the weight of the liver, liver enzymes, bilirubin and resorted lipid profile close to normal level, gallic acid could attenuate liver damage, indicating its hepato-protective impact.

Several studies have shown that oxidative stress is a common characteristic and a major factor in T2DM-related complications (Ceriello 2000; Rösen et al. 2001). Our results showed, in line with those reports, that the untreated DM rats showed a pronounced decrease in the activities of the antioxidant enzymes and disrupted the cellular redox balance in favor of oxidative stress. Gallic acid treatment of diabetic rats showed a marked decrease in the production of MDA along with increased activity of oxidative stress protection enzymes like GSH and SOD, indicating its powerful antioxidant activity.

The untreated diabetic group also showed a substantial elevation in the serum level of fetuin-A in the present work. This rise in fetuin-A is related to the production of insulin resistance in T2DM, according to Ou et al. (2012), which could explain the elevation of HOMA-IR in the current work in untreated diabetic rats. Extracellular signal-regulated $\mathrm{ERK}_{1 / 2}$ and NF- $\mathrm{kB}$ mRNA, which are responsible for the synthesis and release of fetuin-A from the liver, can be explained the findings of current work as elevated levels of fetuin-A in untreated diabetic rats, high blood glucose and lipid serum levels resulted in increased hepatic expression of fetuin-A. In addition, oxidative stress found in untreated diabetic rats may also be responsible for the hepatic synthesis of fetuin-A by activation of the signaling pathways $\mathrm{ERK}_{1 / 2}$ and NF- $\mathrm{KB}$. On the other hand, we have observed that gallic acid administration causes a substantial decrease in fetuin-A levels. Therefore, the hypoglycemic effect of gallic acid observed in the present study could be explained by this finding. In addition, the antioxidant property of gallic acid could decrease both $\mathrm{ERK}_{1 / 2}$ and NF- $\mathrm{KB}$ mRNA hepatic expression. Both of these results explain the decrease in blood glucose levels and insulin resistance in gallic acid-treated diabetic rats.

This result could explain the hypoglycemic effect of gallic acid which observed in the present study. Moreover, the antioxidant property of gallic acid could decrease the hepatic expression of both $\mathrm{ERK}_{1 / 2}$ and NF- $\mathrm{kB}$ mRNA. These all findings explain the improvement of blood glucose levels and insulin resistance in the diabetic rats that treated with gallic acid.

In liver structural and metabolic homeostasis, the Wnt $/ \beta$ catenin pathway plays a pivotal role. In this study, the deficiency of both Wnt 1 and $\beta$-catenin mRNA expression in the liver of the untreated diabetic rats was shown to be responsible for an increase in liver damage in response to T2DM-induced oxidative stress. However, the diabetic rats treated with gallic acid reported a substantial increase in the hepatic Wntl and $\beta$-catenin mRNA expression. Cabrae et al. (2020) suggested that insulin acts as potential novel physiological inducer of the hepatic Wnt $1 / \beta$-catenin pathway. As Funato et al. showed in 2006 that ROS can modulate signaling by the Wnt $1 / \beta$-catenin pathway, another interpretation may be linked to the antioxidant effect of gallic acid (Funato et al. 2006). Taken together, our findings suggest that the hepato-protective effect of gallic acid against oxidative stress-induced by T2DM in the liver can be mediated by Wnt $1 / \beta$-catenin signaling.

\section{Conclusion}

The present study revealed that gallic acid improves T2DMinduced liver dysfunction in male rats via several pathways. 
Our results confirm the hypoglycemic effect of gallic acid through upregulation of hepatic GLUT-4 expression together with increase the number of GLP-1 secreting cells in the terminal ileum. Also, it exerts a powerful antioxidant effect. Moreover, gallic acid improves the hepatic expression of Wnt 1 and $\beta$-catenin with inhibitory effects on the $\mathrm{ERK}_{1 / 2} /$ NF- $\kappa$ B. Those beneficial effects were potentiated following its co-administration with metformin, suggesting its possible complementary effect. Current study confirms the therapeutic effect of gallic acid against diabetic-induced liver dysfunction; however, available data are limited to just cellular and animal studies. Future investigations are essential to define the safety and therapeutic efficacy of gallic acid in humans.

Acknowledgements. The Physiology Department, Faculty of Medicine, Mansoura University and Medical Experimental Research Center (MERC), Faculty of Medicine, Mansoura University, Egypt, acknowledged for their contribution in the experimental part of the present study.

Author contribution. All authors have accepted responsibility for the entire content of this manuscript and approved its submission.

Conflict of interests. The authors declare that there is no conflict of interest.

\section{References}

American Diabetes Association (2014): Diagnosis and classification of diabetes mellitus. Diabetes Care 37 (Suppl. 1), S81-90 https://doi.org/10.2337/dc14-S081

Aughsteen A, Khair B, Suleiman A (2006): Quantitative morphometric study of the skeletal muscles of normal and streptozotocin-diabetic rats. JOP 7, 382-389

Bhat A, Khan A, Alhomida S, Sharma P, Singh R, Paray A (2018): GLP-I secretion in healthy and diabetic Wistar rats in response to aqueous extract of Momordica charantia. BMC Complementary Altern. Med. 18, 1-8

https://doi.org/10.1186/s12906-018-2252-3

Bhattacharya S, Ghosh R, Maiti S, Khan A, Sinha K (2013): The activation by glucose of liver membrane nitric oxide synthase in the synthesis and translocation of glucose transporter- 4 in the production of insulin in the mice hepatocytes. PLoS ONE 8, 1-12 https://doi.org/10.1371/journal.pone.0081935

Cabrae R, Dubuquoy C, Caüzac M, Morzyglod L, Guilmeau S, Noblet B, Fève Z, Postic C, Burnol F, Moldes M (2020): Insulin activates hepatic Wnt/ $\beta$-catenin signaling through stearoylCoA desaturase 1 and Porcupine. Scientific Reports 10, 1-10 https://doi.org/10.1038/s41598-020-61869-4

Ceriello A (2000): Oxidative stress and glycemic regulation. Metabolism 49, 27-29 https://doi.org/10.1016/S0026-0495(00)80082-7

Chen GM, Hu N, Liu L, Xie SS, Wang P, Li J, Xie., Wang GJ, Liu XD (2011): Pharmacokinetics of verapamil in diabetic rats induced by combination of high-fat diet and streptozotocin injection. Xenobiotica 41, 494-500 https://doi.org/10.3109/00498254.2011.558933

Choubey S, Varughese R, Kumar V, Beniwal V (2015): Medicinal importance of gallic acid and its ester derivatives: a patent review. Pharm. Pat. Anal. 4, 305-315

https://doi.org/10.4155/ppa.15.14

Feng T, Tang Y, Jiang X, Zhao W (2017): Anti-diabetic effects of zhuoduqing formula, a chinese herbal decoction, on a rat model of type 2 diabetes. Afr. J. Tradit. Complement. Altern. Med. 14, 42-50

https://doi.org/10.21010/ajtcam.v14i3.5

Funato Y, Michiue T, Asashima M, Miki H (2006): The thioredoxinrelated redox-regulating protein nucleoredoxin inhibits Wntbeta-catenin signalling through dishevelled. Nat. Cell Biol. 8, 501-508 https://doi.org/10.1038/ncb1405

Guo C, Zhang C, Li L, Wang Z, Xiao W, Yang Z (2014): Hypoglycemic and hypolipidemic effects of oxymatrine in high-fat diet and streptozotocin-induced diabetic rats. Phytomedicine 21, 807-814

https://doi.org/10.1016/j.phymed.2014.02.007

Huang XL, He Y, Ji LL, Wang KY, Wang YL, Chen DF, Geng Y, OuYang P, Lai WM (2017): Hepatoprotective potential of isoquercitrin against type 2 diabetes-induced hepatic injury in rats. Oncotarget 8, 101545-101559

https://doi.org/10.18632/oncotarget.21074

Jollow DJ, Mitchell JR, Zampaglione N, Gillette JR (1974): Bromobenzene-induced liver necrosis. Protective role of glutathione and evidence for 3,4-bromobenzene oxide as the hepatotoxic metabolite. Pharmacology 11, 151-169 https://doi.org/10.1159/000136485

Kahkeshani N, Farzaei F, Fotouhi M, Alavi S, Bahramsoltani R, Naseri R, Momtaz S (2019): Pharmacological effects of gallic acid in health and diseases: A mechanistic review. Iran. J. Basic Med. Sci. 22, 225-237

Kappe C, Zhang Q, Nyström T, Sjöholm A (2014): Effects of highfat diet and the anti-diabetic drug metformin on circulating GLP-1 and the relative number of intestinal L-cells. Diabetol. Metab. Syndr. 6, 70

https://doi.org/10.1186/1758-5996-6-70

Kim CH, Kim MS, Youn JY, Park HS, Song HS, Song H, Park JY, Lee KU (2003): Lipolysis in skeletal muscle is decreased in high-fat-fed rats. Metabolism 52, 1586-1592 https://doi.org/10.1016/S0026-0495(03)00328-7

Latha RCR, Daisy P (2011): Insulin-secretagogue, antihyperlipidemic and other protective effects of gallic acid isolated from Terminalia bellerica Roxb. in streptozotocin-induced diabetic rats. Chem. Biol. Interact. 189, 112-118 https://doi.org/10.1016/j.cbi.2010.11.005

Livak J, Schmittgen D (2001): Analysis of relative gene expression data using real-time quantitative PCR and the 2(-Delta Delta $\mathrm{C}(\mathrm{T})$ ) method. Methods 25, 402-408 https://doi.org/10.1006/meth.2001.1262

Loomba R, Sanyal J (2013): The global NAFLD epidemic. Nat. Rev. Gastroenterol. Hepatol. 1, 686-690 https://doi.org/10.1038/nrgastro.2013.171

Loria P, Lonardo A, Anania F (2013): Liver and diabetes. A vicious circle. Hepatol. Research 43, 51-64 https://doi.org/10.1111/j.1872-034X.2012.01031.x 
Mohamed S, Soliman M, Marie S (2016): Mechanisms of echinochrome potency in modulating diabetic complications in liver. Life Sci. 151, 41-49 https://doi.org/10.1016/j.lfs.2016.03.007

Mota M, Banini A, Cazanave C, Sanyal J (2016): Molecular mechanisms of lipotoxicity and glucotoxicity in nonalcoholic fatty liver disease. Metabolism 65, 1049-1061 https://doi.org/10.1016/j.metabol.2016.02.014

Muniyappa R, Chen H, Muzumdar RH, Einstein FH, Yan X, Yue LQ, Barzilai N, Quon MJ (2009): Comparison between surrogate indexes of insulin sensitivity/resistance and hyperinsulinemic euglycemic clamp estimates in rats. Am. J. Physiol. Endocrinol. Metab. 297, E1023-1029 https://doi.org/10.1152/ajpendo.00397.2009

Naidu B, Ponmurugan P, Begum S, Mohan K, Meriga B, RavindarNaik R, Saravanan G (2015): Diosgenin reorganises hyperglycaemia and distorted tissue lipid profile in high-fat diet-streptozotocin-induced diabetic rats. J. Sci. Food Agric. 95, 3177-3182 https://doi.org/10.1002/jsfa.7057

Nyoman I, Utama H, Arjentinia Y, Kardena M, Ayu Mirah Adi A (2017): The differential expression of GLUT4 and glycogen levels on cells of liver and muscle tissues in hyperglycemic and normoglycemic conditions. Bali Medical Journal 6, 84 https://doi.org/10.15562/bmj.v6i3.728

Ohkawa H, Ohishi N, Yagi K (1979): Assay for lipid peroxides in animal tissues by thiobarbituric acid reaction. Anal. Biochem. 95, 351-358 https://doi.org/10.1016/0003-2697(79)90738-3

Öner-İyidoğan Y, Koçak H, Seyidhanoğlu M, Gürdöl F, Gülçubuk A, Yildirim F, Çevik A, Uysal M (2013): Curcumin prevents liver fat accumulation and serum fetuin-A increase in rats fed a high-fat diet. J. Physiol. Biochem. 69, 677-686 https://doi.org/10.1007/s13105-013-0244-9

Ou H.-Y, Wu H-T, Hung H-C, Yang Y-C, Wu J-S, Chang C-J (2012): Endoplasmic reticulum stress induces the expression of fetuinA to develop insulin resistance. Endocrinology 153, 2974-2984 https://doi.org/10.1210/en.2011-2043

Petersen MC, Shulman GI (2018): Mechanisms of insulin action and insulin resistance. Physiol. Rev. 98, 2133-2223 https://doi.org/10.1152/physrev.00063.2017

Pillai Subramanian S (2018): Amelioration of diabetic dyslipidemia by GTF - 231 (Gymnemic acid, Trigonelline and Ferulic acid$2: 3: 1$, a phytochemical preparation studied in high fat diet fed-low dose STZ induced experimental type 2 diabetes in rats. Journal of Diabetes and Obesity 5, 1-9 https://doi.org/10.15436/2376-0494.18.1690

Reed J, Meszaros K, Entes J, Claypool D, Pinkett G, Gadbois M, Reaven M (2000): A new rat model of type 2 diabetes: the fat-fed, streptozotocin-treated rat. Metabolism 49, 1390-1394 https://doi.org/10.1053/meta.2000.17721

Rösen P, Nawroth P, King G, Möller W, Tritschler J, Packer L (2001): The role of oxidative stress in the onset and progression of diabetes and its complications: a summary of a Congress Series sponsored by UNESCO-MCBN, the American Diabetes Association and the German Diabetes Society. Diabetes Metab. Res. Rev. 17, 189-212 https://doi.org/10.1002/dmrr.196
Rotman Y, Sanyal AJ (2017): Current and upcoming pharmacotherapy for non-alcoholic fatty liver disease. Gut 66, 180-190 https://doi.org/10.1136/gutjnl-2016-312431

Seifter S, Dayton S (1950): The estimation of glycogen with the anthrone reagent. Arch. Biochem. 25, 191-200

Silvares RR, da Silva Pereira ENG, Flores EEI, Estato V, Reis PA, Silva IJ da Machado MP, de Castro Faria Neto HC, Tibiriça E, Daliry A (2016): Combined therapy with metformin and insulin attenuates systemic and hepatic alterations in a model of high-fat diet-/streptozotocin-induced diabetes. Int. J. Exp. Pathol. 97, 266-277 https://doi.org/10.1111/iep.12184

Song D, Yin L, Wang C, Wen X (2020): Zhenqing recipe attenuates non-alcoholic fatty liver disease by regulating the SIK1/CRTC2 signaling in experimental diabetic rats. BMC Complement. Med. Ther. 20, 27 https://doi.org/10.1186/s12906-019-2811-2

Srinivasan K, Viswanad B, Asrat L, Kaul CL, Ramarao P (2005): Combination of high-fat diet-fed and low-dose streptozotocintreated rat: a model for type 2 diabetes and pharmacological screening. Pharmacol. Res. 52, 313-320 https://doi.org/10.1016/j.phrs.2005.05.004

Stevens J, Obrosova I, Cao X, Van Huysen C, Greene A (2000): Effects of DL-alpha-lipoic acid on peripheral nerve conduction, blood flow, energy metabolism, and oxidative stress in experimental diabetic neuropathy. Diabetes 49, 1006-1015 https://doi.org/10.2337/diabetes.49.6.1006

Sujithra K, Srinivasan S, Indumathi D, Vinothkumar V (2018): Allyl methyl sulfide, an organosulfur compound alleviates hyperglycemia mediated hepatic oxidative stress and inflammation in streptozotocin-induced experimental rats. Biomed. Pharmacother. 107, 292-302 https://doi.org/10.1016/j.biopha.2018.07.162

Trepanowski F, Mey J, Varady A (2015): Fetuin-A: a novel link between obesity and related complications. Int. J. Obes. 39, 734-741 https://doi.org/10.1038/ijo.2014.203

Vergès B (2015): Pathophysiology of diabetic dyslipidaemia: where are we? Diabetologia 58, 886-899 https://doi.org/10.1007/s00125-015-3525-8

Xiao Y, Chen L, Fan Y, Yan P, Li S, Zhou X (2019): The effect of boletus polysaccharides on diabetic hepatopathy in rats. Chem. Biol. Interact. 308, 61-69 https://doi.org/10.1016/j.cbi.2019.05.013

Zeng Z, Yuan Q, Yu R, Zhang J, Ma H, Chen S (2019): Ameliorative effects of probiotic lactobacillus paracasei NL41 on insulin sensitivity, oxidative stress, and beta-cell function in a type 2 diabetes mellitus rat model. Mol. Nutr. Food Res. 63, 1-9 https://doi.org/10.1002/mnfr.201900457

Zheng J, Xiao K-L, Chen L, Wu C, Hu X, Zeng T, Chen X-Q, Li W-J, Deng X, Li H, Li Y-M (2017): Insulin sensitizers improve the GLP-1 secretion and the amount of intestinal $\mathrm{L}$ cells on high-fat-diet-induced catch-up growth. Nutrition 39-40, 82-91 https://doi.org/10.1016/j.nut.2017.01.002

Received: December 1, 2020

Final version accepted: February 12, 2021 